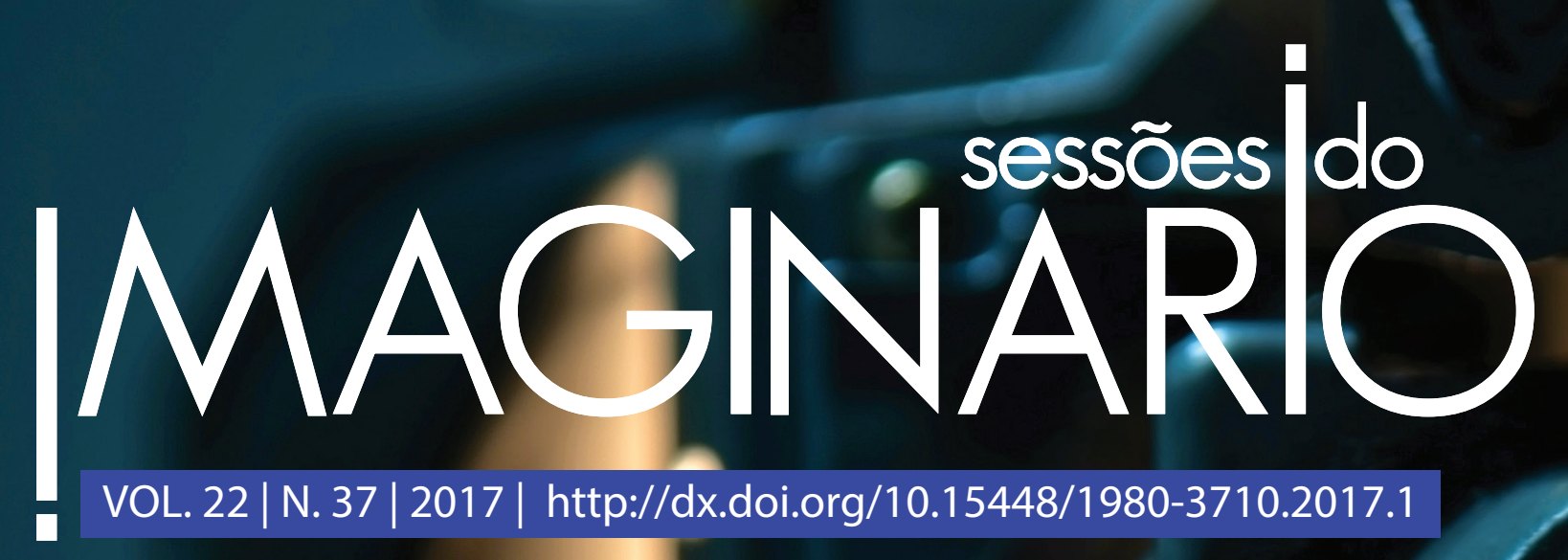

A Comunicação Móvel e Ubíqua do Instagram

Eduardo Campos Pellanda e Melissa Streck
O choque do real em Azul é a cor mais quente

Otacílio Amaral Filho, Sérgio do Espírito Santo Ferreira Júnior e Tarcízio Macedo

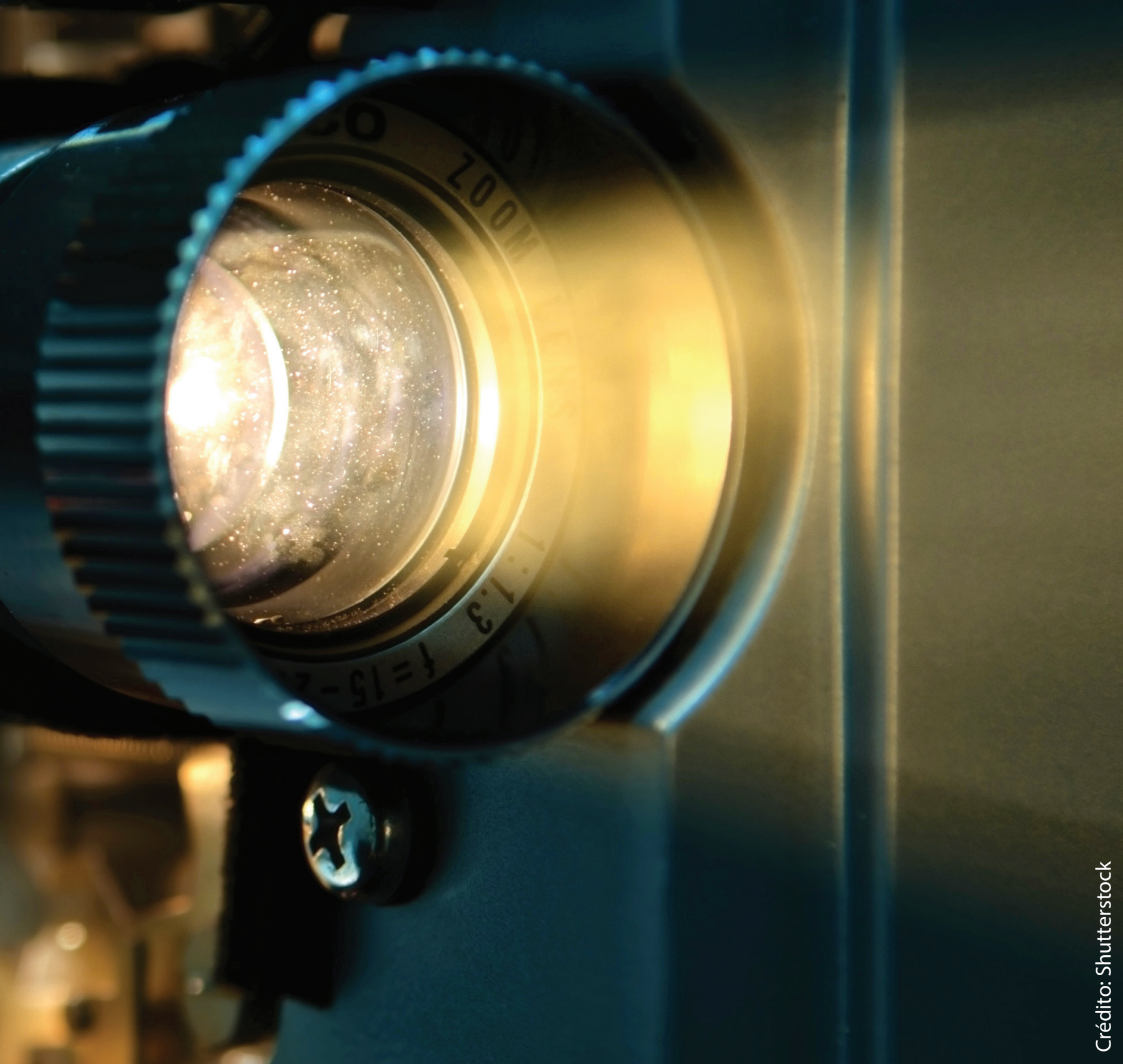

A luta de classes em Que Horas ela Volta?

Mayara Luma Assmar Correia Maia Lobato 


\section{Cinema e guerra: algumas considerações}

\section{Cinema and war: some considerations}

\section{José Wenceslau Caminha Aguiar Junior ${ }^{\top 3}$}

120 PORTO ALEGRE | v. 22 | n. 37 | 2017 | pp. 120-127 DOl: http://dx.doi.org/10.15448/1980-3710.2017.1.27877 Sessões do Imaginário

\section{Resumo}

O que se propõe aqui é estabelecer algumas relações de ordem estética e política entre duas formas de expressão humana: o cinema e a guerra. Embora a guerra esteja presente na história da humanidade desde o seu início e o cinema seja uma invenção relativamente recente, desde que o registro cinematográfico dos acontecimentos passou a existir estabeleceu-se uma relação permanente entre a cinematografia mundial e os conflitos bélicos, seja através de imagens documentais ou obras ficcionais que retratam esta atividade, que - ao que tudo indica nos acompanhará enquanto nossa espécie habitar este planeta: a guerra.

\section{Palavras-chave}

Cinema; guerra;

documentário; ficção.

\section{Abstract}

What is proposed here is to establish some relations of aesthetic and political order between two forms of human expression: cinema and war. Although war has been present in the history of mankind since its inception and filmmaking is a relatively recent invention, ever since the cinematographic record of events came into being, a permanent relationship has been established between universal cinematography and military conflicts, whether through documentary images or fictional works, which portray the activity that - it seems - will accompany us while our species inhabit this planet: war.

\section{Keywords}

Cinema; war; documentary; fiction. 


\section{Introdução}

Nos grandes desfiles, nos comícios gigantescos, nos espetáculos esportivos e guerreiros, todos captados pelos aparelhos de filmagem e gravação, a massa vê o seu próprio rosto. Esse processo, cujo alcance é inútil enfatizar, está estreitamente ligado ao desenvolvimento das técnicas de reprodução e registro. [...] Isso significa que os movimentos de massa e, em primeira instância, a guerra, constituem uma forma do comportamento humano especialmente adaptado ao aparelho (Benjamin, 1986, p. 33).

Em 1995, foi produzido o filme Lumière e companhia (Lumière et compagnie, Theodoros Angelopoulos et al., 1995) projeto criado pela fotógrafa e diretora Sarah Moon em comemoração aos 100 anos da primeira projeção cinematográfica. Quarenta cineastas, entre eles Wim Wenders, Arthur Penn, Costa-Gavras e Claude Lelouch, foram convidados a dirigir um curta utilizando o cinematógrafo original dos irmãos Lumière ${ }^{22}$ e um rolo de filme com a metragem original utilizada pela câmera, com 52 segundos de duração. O francês Lelouch usou esse pequeno tempo para realizar uma homenagem ao cinema e ao seu dispositivo principal, a câmera cinematográfica: em uma tomada única ele filmou um casal que se beija sobre uma plataforma giratória oculta. Ao girar, o casal atua como uma engrenagem, que nas câmeras e nos projetores cinematográficos analógicos é responsável por puxar o filme; só que ali ela "puxa" uma sequência de câmeras com seus cinegrafistas, diretores e iluminadores, que passam filmando a cena. Em meio aos cameramen, vê-se um cinegrafista do exército

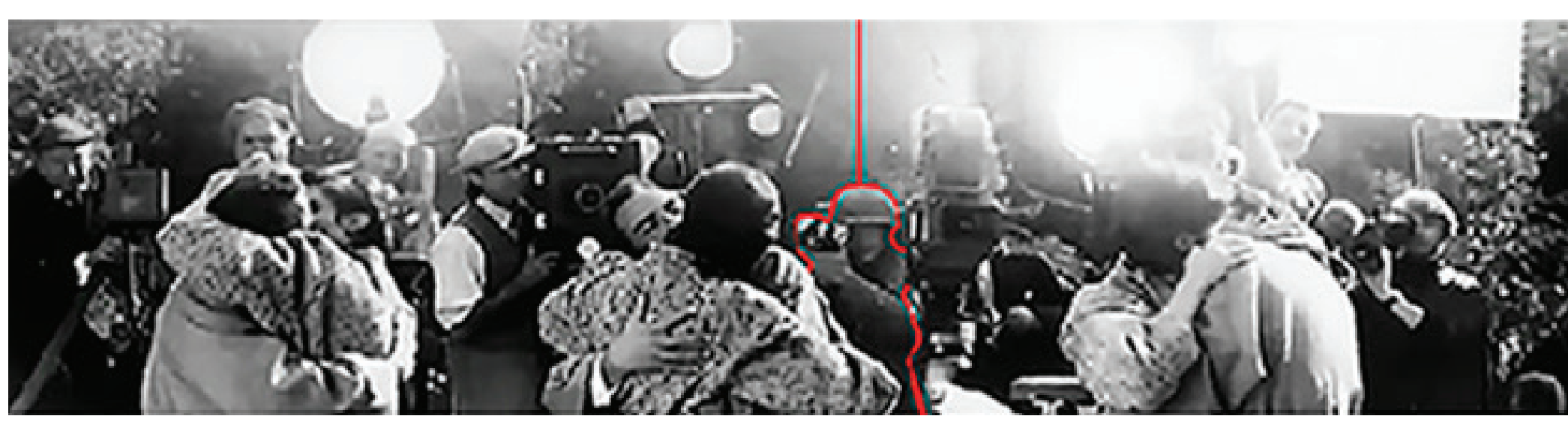

Figura 1: Montagem com as imagens do segmento de Claude Lelouch no filme "Lumière et Compagnie". Fonte: Youtube, 2016.

americano, simbolizando a linha divisória entre o cinema pré e pós Segunda Guerra Mundial, o conflito armado mais importante da história da humanidade, cujos desdobramentos se fazem sentir até os dias de hoje em todas as áreas da atividade humana (Figura 1).

Desde o momento em que o cinema passou a existir, o relacionamento entre essa nova forma de capturar e exibir os eventos do mundo, e os conflitos armados entre as nações, deram início a uma longa e duradoura relação, às vezes, amorosa, outras vezes, conflituosa ${ }^{33}$ : 0 surgimento do cinema respondeu à ânsia por uma nova visualidade, presente na sociedade ocidental e urbana do final do século XIX, cujo ritmo era cada vez mais acelerado. Essa imagem animada não poderia ser de natureza contemplativa, mas, ao contrário, veloz como o disparo de uma arma. Para Camile Paglia:

A agressão e projeção fálicas são intrínsecas à conceitualização universal. Seta, olho, canhão, cinema: o ígneo facho do cinema é o nosso moderno caminho de transcendência apolínea. O cinema é a culminação do obsessivo impulso masculino, mecani- cista, na cultura ocidental. É um atirador apolíneo, demonstrando a relação entre agressão e arte ( $\mathrm{Pa}-$ glia, 1993, p. 40).

Entre as décadas de 1870 e 1890, o inglês Eadweard Muybridge e o francês Etienne-Jules Marey foram os primeiros a documentar seres humanos e animais se deslocando no espaço e no tempo. As experiências com o fuzil cronofotográfico de Marey (Figura 2) visavam registrar os corpos enquanto "máquinas biológicas" em movimento. Sobre o fuzil cronofotográfico de Marey e o desejo deste pesquisador em registrar o voo dos pássaros com o auxílio da fotografia instantânea, Pénaud escreveu: "[...] Seria uma caça não ao pássaro, mas à sua imagem" (Pénaud, apud Mannoni, 2003, p. 327). Essa afirmação é significativa, pois seu autor dava testemunho de uma nova forma de captura dos seres do mundo, capaz de realizar doze snapshots/instantâneos em um segundo, mas que já não mais abatia os pássaros, como o inglês Henry Hawker havia descrito sessenta anos antes ${ }^{44}$, mas os registrava fotoquimicamente. 


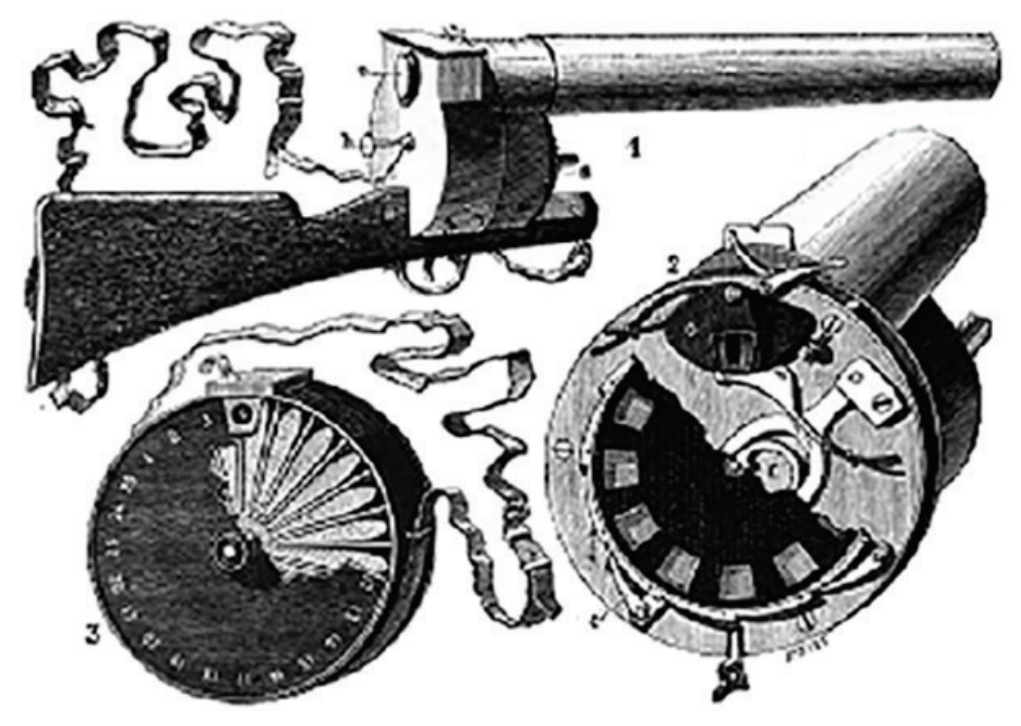

Figura 2: Fuzil cronofotográfico de Etienne-Jules Marey. Fonte: Bigriotsquad, 2016.

Jonathan Crary coloca a câmera fotográfica (que posteriormente teria como desdobramento a câmera cinematográfica) como o grande exemplo do objeto produzido no século XIX já dentro de parâmetros industriais, e associa esse modus operandum à produção em série de armamento (Crary, 1990). De fato, essas duas ramificações do novo modelo industrial, que então se instaurava, tinham muito mais em comum do que se poderia supor... O cinema, lanterna mágica produzida em escala industrial, se inseriu definitivamente no imaginário do homem moderno, tornando-se um meio de comunicação de massas e trazendo novos paradigmas visuais ao fenômeno da modernidade.

Em uma sociedade que se reconfigurava sob novos parâmetros da velocidade e do deslocamento, o cinema, cujo termo em inglês é, sintomaticamente, motion picture - imagem em movimento - respondeu amplamente a essa nova necessidade visual. Além das imagens docu- mentais, o cinema se tornou a grande fábrica de fantasias: os sonhos - ou pesadelos - de roteiristas e diretores são compartilhados por uma plateia imersa em um sonho acordado, como percebe Benjamin: "O cinema introduziu uma brecha na velha verdade de Heráclito segundo a qual o mundo dos homens acordados é comum, o dos que dormem é privado" (Benjamin, 1986, p. 190).

$O$ francês Fernand Léger foi um dos artistas que tiveram uma visão clara dessa nova cultura emergente, urbana e massificada, cujo resultado mais palpável era objetos - de filmes a armas - produzidos em larga escala. Logo após o fim da Primeira Guerra Mundial, ele afirmou: “Esta culatra de um canhão 75 aberta em pleno sol me ensinou mais, no que concerne à minha evolução plástica, do que todos os museus do mundo" (Neret, apud Huchet, 1994, p. 205). Desde a invenção dos processos fotoquímicos, foto-eletrônicos e digitais de registro imagético, se estabeleceu uma relação estreita entre as imagens produzidas ao longo dos séculos XIX XX e XXI e os conflitos bélicos que ocorrem pelo mundo.

\section{Imagens da guerra, guerra de imagens}

A Primeira Grande Guerra foi o primeiro conflito armado entre as nações operacionalizado em escala industrial, no qual foram utilizadas inovações técnicas como o avião, o tanque de guerra, o lança-chamas e os gases letais. Um dos efeitos provocados nos combatentes durante a permanência no território das batalhas foi a mudança na percepção visual da realidade, que, a partir daí, nunca mais seria a mesma. Essa guerra produziu um forte impacto nas gerações que a vivenciaram: os movimentos modernistas, tanto aqueles eivados pela descrença e a derrisão, como o Dadaísmo, quanto os movidos pelo desejo de um mundo renovado e espiritualmente evoluído, como o Neoplasticismo - todos nasceram à sombra daquele conflito. Comentando o ambiente onde se desenrolavam os combates, Paul Virilio afirma:

[...] Para o homem da guerra, a função da arma é a função do olho. É, portanto, normal que a violenta violação cinemática do continuum espacial - deflagrada pela arma aérea - e os notáveis progressos das tecnologias de guerra tenham literalmente rompido, a partir de 1914, com a antiga visão homogênea (Virilio, 1993, p. 37).

Vejamos a declaração de Antoine de Saint-Éxupery sobre sua experiência como piloto e a capacidade da guerra em instaurar uma ótica particular sobre o mundo através do olhar dos pilotos, que agora podiam observar as batalhas das alturas e vê-las reduzidas a uma dimensão miniaturizada:

Da vertical eu via somente bibelôs antigos sob um cristal puro que não tremia. Eu me debruço sobre vitrines de museu, domino uma grande placa espeIhada, a grande placa de minha vitrine. Lá embaixo os homens, micróbios em uma lâmina de microscópio... Eu sou um sábio glacial e para mim a guerra deles não é nada mais do que uma experiência de laboratório (Saint-Éxupery, apud Virilio, 1993, p. 167).

Meio audiovisual onde se materializam os anseios, fantasias e sonhos humanos, o cinema é a mais extraordinária das formas de expressão artística, capaz de nos 
retirar do mundo e, durante a projeção, libertar nossas mentes e anular as limitações de toda ordem que nos são impostas pela realidade. Como afirma Walter Benjamin:

Nossos cafés e nossas ruas, nossos escritórios e nossos quartos alugados, nossas estações e nossas fábricas pareciam aprisionar-nos inapelavelmente. Veio então o cinema, que fez explodir esse universo carcerário com a dinamite dos seus décimos de segundo, permitindo-nos empreender viagens aventurosas entre as ruínas arremessadas à distância (Benjamin, 1986, p. 189).

Com os filmes de guerra, o efeito se repete: podemos assistir aos conflitos bélicos que já ocorreram, que estão ocorrendo e até mesmo conflitos entre humanos e alienígenas; vivenciar os combates sem sermos feridos ou mortos: eles são um dos gêneros clássicos da indústria cinematográfica e sempre atraíram multidões ao cinema.

A Primeira Guerra Mundial foi tema de filmes que estão na lista das grandes películas da cinematografia mundial, como Asas (Wings, 1927) (Figura 3), criado a partir das experiências do próprio diretor William A. Wellman como piloto de combate da Esquadrilha Lafayette ${ }^{55}$.

As cenas de combate de Nada de novo no front, de Lewis Milestone (All quiet on the western front, 1930), (Figura 4) também sobre a Primeira Guerra, possuem uma qualidade cinematográfica que nada deixa a dever aos atuais filmes de guerra.

Não é por acaso que esse gênero de filme é um dos mais populares da história do cinema: suas imagens atraem multidões, mesmo quando os heróis retratados

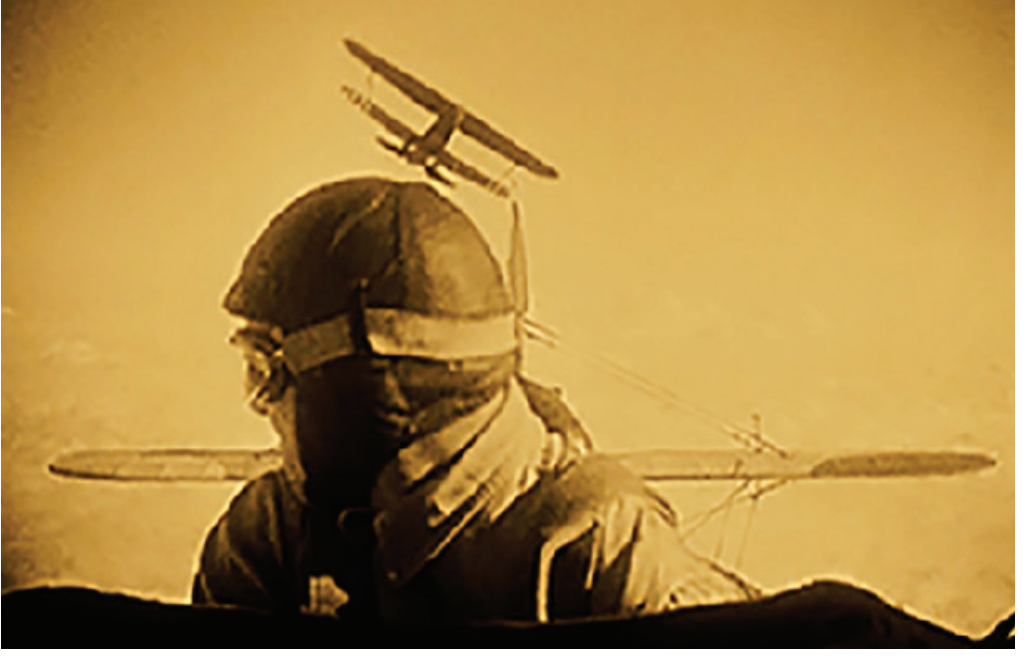

Figura 3: Asas (Wings, William A. Wellman, 1927).

Fonte: Dvdbeaver, 2016

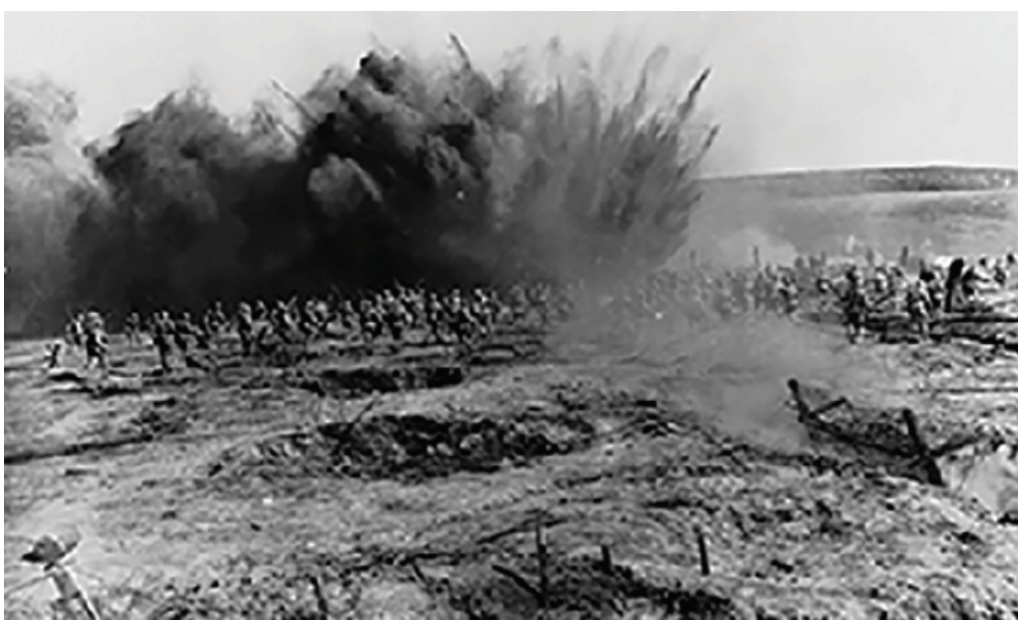

Figura 4: Nada de novo no front (All quiet on the western

front, Lewis Milestone, 1930). Fonte: Uphe, 2016.

são militares do exército nazista, como é o caso de $A$ cruz de ferro, de Sam Peckinpah (Cross of iron, 1977), (Figura 5) uma exceção à regra, já que esses são geralmente tratados como vilões.

Ainda hoje, enquadramentos e movimentos de câmera desses filmes são reencenados por cineastas como

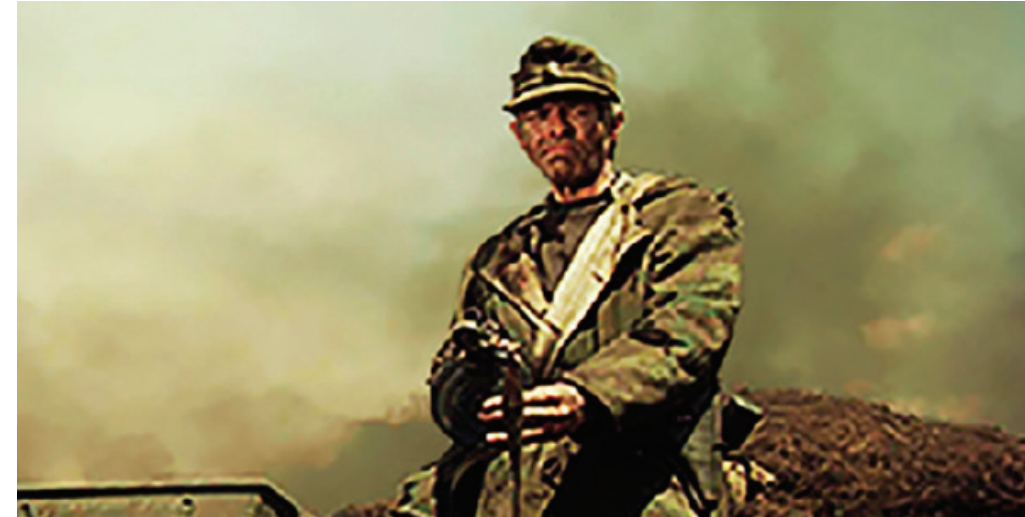

Figura 5: Cruz de Ferro (Cross of iron, Sam Peckimpah, 1977). Fonte: Mubi, 2016

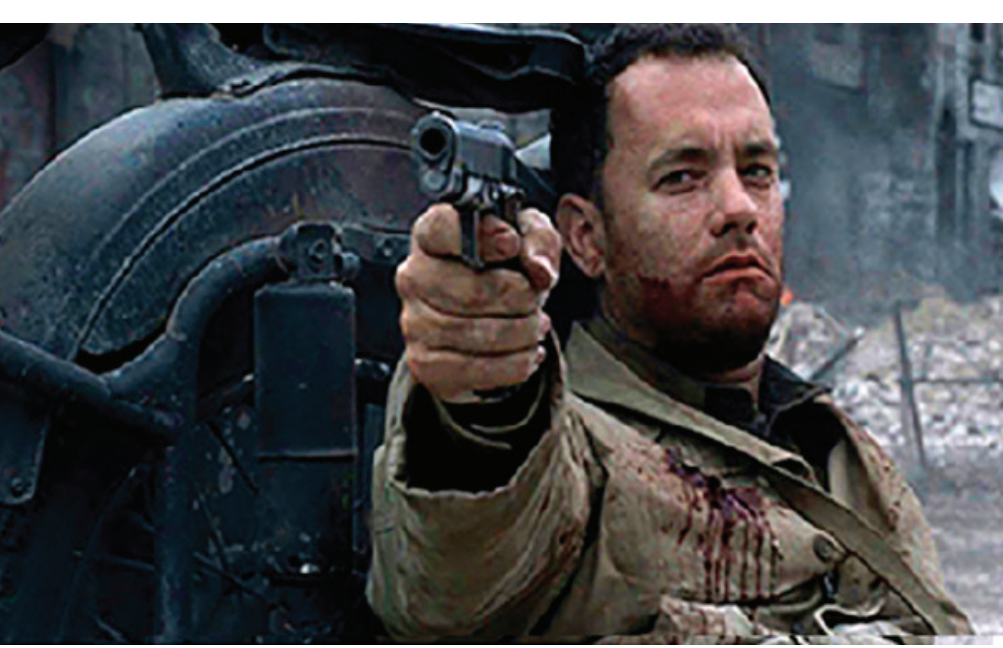

Figura 6: O resgate do soldado Ryan (Saving private Ryan, Steven Spielberg, 1998). Fonte: Express Elevator to Hell, 2016.

Steven Spielberg, cujo filme O resgate do soldado Ryan (Saving private Ryan, 1998) (Figura 6) é uma verdadeira colagem de referências de filmes de guerra, incluindo documentários realizados durante a Segunda Guerra, como A batalha das Marianas (The battle for the Marianas, Gordon Hollingshead, 1944) sobre o cenário de guerra no Pacífico. 
Antes de se tornar diretor de longas metragens, Richard Brooks serviu na Unidade de Filmes da Infantaria Naval norte-americana. Em depoimento para o documentário A história do Oscar: os primeiros 50 anos (The academy award winners: the first 50 years, Jeff Forrester, 1994), Brooks conta que, antes da invasão de Saipan, ilha do arquipélago das Marianas, perguntou ao comandante americano general "Mad" Holland Schmidt se os cinegrafistas da Marinha poderiam levar pistolas, já que com elas teriam condição de revidar os tiros. O general respondeu: "Apenas disparem aquela maldita câmera. Não disparem nenhuma pistola, porque aquela câmera é o olho do mundo".

Ao chamar a câmera do cinegrafista de "olho do mundo", o general Schmidt reafirmava a visão de que essa é capaz de funcionar como "olho da verdade", capaz de "observar" por todos aqueles que, afortunadamente, não estivessem em Saipan no momento da invasão. A veracidade das imagens estava explicitamente colocada do lado das tropas aliadas, o que é compreensível: naquele momento, o mundo estava dividido em dois grupos claramente antagônicos de nações: o dos "mocinhos" e o dos "bandidos". Quando hoje vemos as imagens da guerra do Pacífico, por exemplo, os filmes mostram o ponto de visto dos aliados; e não poderia ser diferente: quem vence a guerra escreve a História.

A guerra é um dos maiores espetáculos produzidos pelo homem: por mais impactantes e assustadoras, as imagens dos conflitos bélicos, sejam provenientes de arquivos ou, como ocorre atualmente, transmitidas em tempo real, atraem o olhar do grande público. É lá o "palco" das batalhas onde se "encena" a destruição: o "teatro ${ }^{66}$ de operações". No seu livro, Arte e sociedade, Baynes pergunta se essa atração:
[...] é a sublimação da agressão ou é a ressonância continuada do cumprimento dos desejos? Em qualquer dos casos, a guerra desempenha um papel de inquietante importância na vida espiritual da sociedade contemporânea. [...] A verdade pouco agradável parece consistir em que a cultura da guerra é como o cultivo tradicional no microcosmo, e por isto exerce uma fascinação tão poderosa (Baynes, 1976, p. 231)

Inicialmente, as imagens documentais das guerras nos chegavam através de películas cinematográficas produzidas pelos próprios militares ou pelos correspondentes de guerra (Primeira e Segunda Guerra Mundial e Guerra da Coreia); posteriormente foram acrescentadas as imagens videográficas transmitidas via satélite, ainda que com alguma defasagem entre sua captação e sua transmissão (Guerra do Vietnã) finalmente, tivemos a transmissão em tempo real (Guerras do Golfo e do Iraque). A guerra do Vietnã foi a primeira guerra televisionada: a população norte-americana pôde ver as imagens de parentes e amigos envolvidos nos intensos combates na selva, sendo feridos ou mortos. Isso gerou uma onda de protestos dentro e fora do EUA, o que acabou solapando aquela empreitada militar norte-americana e que, segundo Laymert Garcia dos Santos, levou os militares do Pentágono a formularem o seguinte axioma: "Guerra televisionada é uma guerra perdida" (Santos apud Parente, 1993, p. 158). Já na Guerra do Golfo e na invasão do Iraque, as imagens pareciam saídas de um filme da série Guerra nas estrelas (Star Wars, criada pelo cineasta George Lucas, iniciada em 1977 e composta por duas trilogias) com as emissoras raramente exibindo cadáveres: essa "estetização" na cobertura dos conflitos continua e se torna cada vez mais sofisticada.

A guerra pode fascinar até mesmo aqueles que estão em meio aos combates. Segundo Virilio, esse estado de excitação hipnótica: "[...] é a mesma sensação experimentada pelos jovens recrutas do exército americano, que descreveram sua experiência com perfeição ao utilizar a expressão 'Nós vamos ao cinema' quando ocupam postos avançados e perigosos" (Virilio, 1993, p.99).

Um dos mais extraordinários filmes de guerra é Dr. Fantástico, de Stanley Kubrick (Dr. Strangelove or: how I learned to stop worrying and love the bomb, 1964), cuja trama tem como núcleo o conflito atômico entre os EUA e a URSS e a decorrente aniquilação da humanidade. No filme, o comandante da Força Aérea dos Estados Unidos, Jack D. Ripper (Sterling Hayden), lança uma esquadrilha de bombardeiros estratégicos B-52 em direção ao território soviético, onde lançarão suas bombas termonucleares.

Dr. Fantástico é um "sanduíche", cuja parte externa - o início e o fim do filme - é composta por imagens documentais de arquivo e, o "recheio", pela ficção em si. Ao utilizar imagens reais de um abastecimento nos créditos iniciais do filme e, no final, de explosões atômicas, Kubrick explicitava a possibilidade concreta do fim da civilização (Aguiar Junior, 2015). A abertura mostra um B-52 sendo abastecido por um avião-tanque KC-135: ambos flutuam acima das nuvens. A fotografia, com total profundidade de campo, se estende até onde a vista alcança: um território neutro, sem referências geográficas. Como trilha sonora, temos a versão orquestrada de Try a little tenderness (Experimente 
um pouco de ternura): as imagens e a música produzem uma profunda sensação de paz e harmonia, e observamos uma coreografia sendo encenada nas camadas superiores da estratosfera (Aguiar Junior, 2015).

Ela nos traz à lembrança outra sequência aérea, também de abertura, realizada vinte e nove anos antes pela cineasta Leni Riefenstahl para o documentário O triunfo da vontade (Triumph des willens, 1935). O avião Junkers ju 52 surge em meio às nuvens, levando no seu interior Adolf Hitler para o congresso do partido nazista em Nuremberg. Em ambas as sequências, os aviões estão em ambientes idílicos, mas são máquinas que carregam em seu interior uma força oculta e inaudita de destruição (Figura 7).

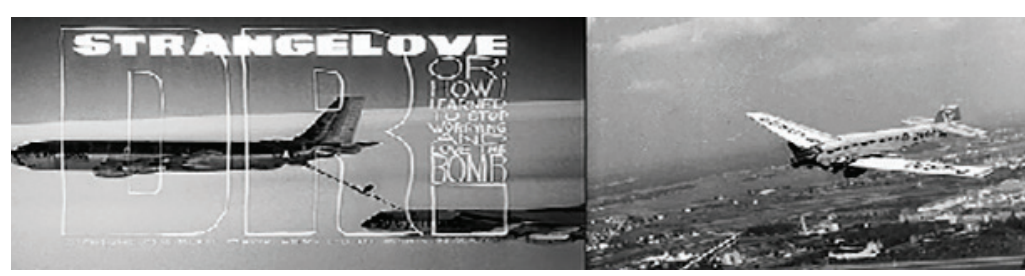

Figura 7: Dr. Fantástico (Dr. Strangelove, Stanley Kubrick, 1964). Fonte: Vimeo, 2016.

Ainda no filme Dr. Fantástico, após uma série de peripécias e situações tragicômicas, a tripulação do B-52 consegue finalmente atingir uma base soviética de mísseis e dispara a "Máquina do Juízo Final"77. Surge então a sequência de explosões atômicas: o fim do mundo, tendo como fundo musical a reconfortadora canção, lançada durante a Segunda Guerra Mundial, We'll meet again (Nos encontraremos novamente) gravada pela cantora Vera Lynn. Segundo Virilio, Kubrick:

[...] foi ao essencial de uma imagem de guerra em que não subsiste nada além do registro dos estados sucessivos do material destruído e uma voz distante, cantando o desejo de um reencontro que, simultaneamente, se torna fisicamente impossível, mas desta vez para sempre e para todo o mundo (Virilio, 1993, p. 45, apud Aguiar Junior, 2015, p. 8).

\section{Espetáculos cinematográficos: de guerras a vulcões}

Tanto a guerra quanto o cinema são capazes de produzir espetáculos visuais cuja potência é da ordem do alucinatório. Ainda na década de 1930, Benjamin definiu com clareza os poderes da imagem cinematográfica de nos lançar em uma vertigem ótica:

Ela (a câmara) nos abre, pela primeira vez, a experiência do inconsciente ótico, do mesmo modo que a psicanálise nos abre a experiência do inconsciente pulsional. [...] Muitas deformações e estereotipias, transformações e catástrofes que o mundo visual pode sofrer no filme afetam realmente esse mundo nas psicoses, alucinações e sonhos (Benjamin, 1986, p. 189-190).

Se somados, os resultados podem ser vertiginosos como Francis Coppola tão bem explorou em Apocalypse now (1979) (Figura 8): ao assistir o filme, a impressão é a de se estar diante de uma alucinação criada a partir da dinamite, da pólvora e da gasolina. Nele, tanto a trama em si quanto os personagens parecem estar imersos em uma viagem psicodélica, na qual se dissolve a fronteira entre o que é real ou um delírio dos tripulantes daquele barco da morte. Nas guerras, a percepção da realidade torna-se difusa, como escreve Virilio, ao tratar das alterações psicológicas nelas geradas:

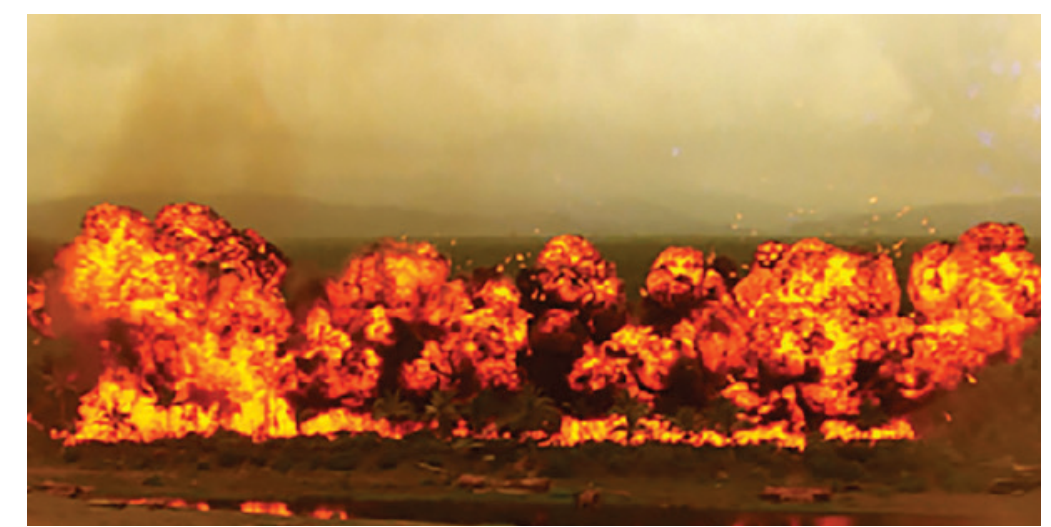

Figura 8: Triunfo da vontade (Triumph dês Willens, Leni Riefensthal, 1935). Fonte: keyword-suggestions, 2016

Não existe, portanto, guerra sem representação ou arma sofisticada sem mistificação psicológica, pois, antes de serem instrumentos de destruição, as armas são instrumentos de percepção, ou seja, estimulantes que provocam fenômenos químicos e neurológicos sobre órgãos dos sentidos e o sistema nervoso central, afetando as reações e a identificação e diferenciação dos objetos percebidos (Virilio, 1993, p. 45, grifos do autor).

O fotojornalista Dith Pran, retratado no filme Os gritos do silêncio (The killing fields, 1984), dirigido por Roland Joffé, relembrou no artigo de 2003: The sky was falling; Cambodia, 1970, como era assistir os aviões norte-americanos bombardeando as posições comunistas no Camboja: "Se você não se lembra do perigo, aquilo se parece com uma performance. [...] Era lindo, como fogos de artifício. A guerra é linda se você não é morto" (Pran, 2003).

A ideia de se assistir imagens de eventos de grande impacto emocional, de guerras a desastres naturais, 
como se fossem um filme está impregnada no nosso imaginário. Em um documentário sobre o vulcão Pinatubo, nas Filipinas, a base aérea norte-americana de Clark, próxima do vulcão, foi evacuada devido à iminência de uma grande erupção, permanecendo lá apenas os vulcanólogos e a equipe de documentaristas que os acompanhava. A erupção de fato aconteceu: no seu auge um dos vulcanologistas foi até a cozinha, preparou e começou a comer pipoca. Perguntado por seu colega cientista do porquê estava fazendo aquilo em um momento de tamanho perigo, ele respondeu: "Eu sempre como pipoca nessa parte dos filmes"! (In the path of a killer volcano, Rob Whittlesey, 1993).

\section{Referências}

AGUIAR JUNIOR, José Wenceslau Caminha. Balés eróticos, balés mecânicos: as coreografias do império. E-COM, Belo Horizonte, v. 8, n.1, p. 01-11, 2015.

BAYNES, Ken. Arte y sociedad. Barcelona: Blume, 1976.

BENJAMIN, Walter. A obra de arte na era de sua reprodutibilidade técnica. In: BENJAMIN, Walter. Magia e técnica, arte e política: obras escolhidas. São Paulo: Brasiliense, 1986.

BIGRIOTSQUAD. Disponível em: <htpps//bigriotsquad. blogspot.com.br/2014/10/chronophotography-part-2october-26-2014.html.>. Acesso em: 9 ago. 2016.

CRARY, Jonathan. Techniques of the observer: on vision and modernity in the nineteenth century. Cambridge: MIT Press, 1990.
DVDBEAVER. Disponível em: <http://dvdbeaver.cofilm3/ bluray_review56/wings_blu-ray.html>. Acesso em: 9 ago. 2016.

EXPRESS ELEVATOR TO HELL. Disponível em: <https:// expresselevatortohell.com/2013/01/28/saving-privateryan-1998-review/>. Acesso em: 06 ago. 2016.

GRANIMAGINADOR. Disponível em: <http:// granimaginador.es/2016/05/05levantar-se-en-armas/>. Acesso em: 09 ago. 2016.

HUCHET, Stéphane. Do quadro ao cinema: a equivalência da arte e do mundo segundo Fernand Léger. Gávea, Rio de Janeiro, v. 11, n. 11, p. 203-215, abr. 1994.

KEYWORD-SUGGESTIONS. Disponível em: $<\mathrm{http}: / / \mathrm{www}$. keyword-suggestions.com/dGFudGVqdQ/>. Acesso em: 09 ago. 2016.

MANNONI, Laurent. A grande arte da luz e da sombra: arqueologia do cinema. São Paulo: SENAC São Paulo, UNESP, 2003.

MUBI. Disponível em: <https://mubi.com/films/cross-ofiron>. Acesso em: 06 ago. 2016.

PAGLIA, Camille. Personas sexuais: arte e decadência de Nefertite a Emily Dickson. São Paulo: Companhia das Letras, 1993.

PARENTE, André (Org.). Imagem-máquina: a era das tecnologias do virtual. Rio de Janeiro: Ed. 34, 1993.
PRAN, Dith. The sky was falling; Cambodia, 1970. The New York Times, 30 mar. 2003. Disponível em: < http:// www.nytimes.com/2003/03/30/magazine/the-sky-wasfalling-cambodia-1970.html>. Acesso em: 06 ago. 2016.

TEATRO. In: HOUAISS, Antônio; VILLAR, Mauro de Salles. Dicionário Houaiss da língua portuguesa. Rio de Janeiro: Objetiva, 2001, p. 2682.

UPHE. Disponível em: <https://uphe.com/movies/allquiet-on-the-western-front>. Acesso em: 06 ago. 2016.

VIMEO. Disponível em: <http://vimeo.com/31907879>. Acesso em: 06 ago. 2016.

VIRILIO, Paul. Guerra e cinema. São Paulo: Página Aberta, 1993.

YOUTUBE. Disponível em: <https://www.youtube.com/ watch?v=lafQqbsht_g\&list=PL3A787472EOBDD67F\&index=20>. Acesso em: 7 ago. 2016.

Referências audiovisuais

ARMY, United States. CORPS, United States. NAVY, United States. HOLLINGSHEAD, Gordon. A batalha pelas Marianas (The battle for the Marianas). [Documentário]. Produção das Forças Armadas Norteamericanas, direção de Gordon Hollingshead. 1944. P \& B. Son. Disponível em: <https://www.youtube.com/ watch?v=Qc6W1gLyqzY>. Acesso em: 17 fev. 2017.

BRYCE, lan; GORDON, Mark; LEVINSOHN, Gary; SPIELBERG, Steven. O resgate do soldado Ryan (Saving private Ryan) [Filme]. Produção de lan Bryce; 
Mark Gordon; Gary Levinsohn; Steven Spielberg, direção de Steven Spielberg. USA, 1998, 2h49min. color. son.

COPPOLA, Francis. Apocalyse now. [Filme]. Produção e direção de Francis Coppola, USA, 1979, 2h33min. color. son.

EDELSTEIN, Neal; SERVAN-SCHREIBER, Fabienne; ANGELOPOULOS, Theodoros et al. Lumière e companhia (Lumière et compagnie). [Filme]. Produção de Neal Edelstein; FabienneServan-Schreiber, direção de Theodoros Angelopoulos et al. França, 1995, 1h28min. color, p\&b. son.

FORRESTER, Jeff; KELLEY, Brian. A história do Oscar: os primeiros 50 anos (The academy award winners: the first $\mathbf{5 0}$ years). [Documentário]. Produção de Jeff Forrester e Brian Kelley, direção de Jeff Forrester. USA, 1994, 476min. color. son.

HARTWIG, Wolf C.; PECKINPAH, Sam. Cruz de ferro (Cross of iron). [Filme]. Produção de Wolf C. Hartwig, direção de Sam Peckinpah. UK, West Germany, 1977, 2 h12min. color. Son.

HUBBARD, Lucien. Asas (Wings) [Filme]. Produção de Lucien Hubbard, direção de William A. Wellman. USA, 1927. 144 min. p\&b. mudo.

KUBRICK, Stanley. Dr. Fantástico (Dr. Strangelove or: how I learned to stop worring and love the bomb). [Filme]. Produção e direção de Stanley Kubrick. USA, UK, 1964, 1h35min. p\&b. son.

LAEMMLE JR., Carl; MILESTONE, Lewis. Nada de novo no front (All quiet on the western front). [Filme]. Produção de Carl Laemmle Jr., direção de Lewis Milestone.USA 1930, 2h16min. p\&b. mudo.

PUTTNAM, David; JOFFÉ, Roland. Os gritos do silêncio (The killing fields). [Filme]. Produção de David Puttnam Direção de Roland Joffé. UK, 1984, 2h21min. color. son.

RIEFENSTAHL, Leni. 0 triunfo da vontade (Triumph des willens). [Documentário]. Produção e direção: de Leni Riefenstahl. Alemanha, 1935, 1h54min. p\&b. son.

WHITTLESEY, Rob. Mt. Pinatubo explosion at Clark Air Base, Philippines. Part 2. In: In the path of a killer volcano. [Documentário]. Direção de Rob Whittlesey. 1993. color. son. Disponível em: <https://www. youtube.com/watch? v=PvpBbiCG-7s >. Acesso em: 06 ago. 2016.

\section{Notas}

1 Doutor em Linguagens Visuais - Escola de Belas Artes/UFRJ. Mestre em Artes Visuais e Bacharel em Artes Plásticas - Escola de Belas Artes/UFMG. Leciona na Escola Guignard/UEMG (Escola Guignard: Rua Ascânio Burlamarque, 540 Mangabeiras. Cep: 30315-030. Belo Horizonte/MG). E-mail: laucaminha@yahoo.com.

2 Restaurado por Philippe Poulet, do Museu do Cinema de Lyon.

3 Os filmes de guerra, sejam eles documentais ou obras ficcionais, têm servido tanto para saudar a guerra como um instrumento válido a serviço do Estado, quanto para criticar essa prática humana com algo terrível, brutal e que deveria ser banida da humanidade.
4 Em inglês o termo para "instantâneo" fotográfico é snapshot, cujo significado inicial foi "tiro disparado sem pontaria em um alvo que aparece repentinamente e por um período de tempo muito curto", usado pela primeira vez em 1808 por Henry Hawker: ele anotou em seu diário que quase todos os pássaros que ele havia matado naquele dia tinham sido atingidos por um snapshot.

5 Esquadrilha formada por pilotos norte-americanos que combateram ao lado dos franceses durante a Primeira Guerra Mundial.

6 A palavra teatro se origina dos termos gregos théa, espetáculo, e tron, instrumento: uma "máquina de espetáculo" (Houaiss, 2001, p. 2682).

7 No filme, a União Soviética havia criado a "Máquina do Juízo Final", que consistia em muitas bombas atômicas revestidas com "Cobalto-tório G" e ligadas a uma rede de computadores montada para detoná-las automaticamente caso um ataque nuclear atingisse o país. A Terra seria envolvida em uma nuvem radioativa, que extinguiria a vida no planeta. $O$ dispositivo não podia ser desmontado e era programado para explodir caso houvesse qualquer tentativa nesse sentido. 